\title{
Vulnerability of Atlantic herring larvae to predation by yearling herring*
}

\author{
Lee A. Fuiman \\ University of Texas at Austin, Marine Science Institute, Port Aransas, Texas 78373, USA and \\ Dunstaífnage Marine Research Laboratory, Oban, Argyll, Scotland
}

\begin{abstract}
This study quantifies age-related changes in the vulnerability of Atlantic herring Clupea harengus larvae to predation by larger herring through experimental investigations of capture probability in the laboratory and gross vulnerability in large enclosures (mesocosms). Seventy-six laboratory predation trials were staged involving larvae averaging 8.6 to $32.0 \mathrm{~mm}$ in length (4 to $118 \mathrm{~d}$ posthatching). In all, 1067 attacks were observed. The proportion of larvae responding to an attack was constant (6.2\%) for lengths $<26 \mathrm{~mm}$. Responsiveness of larger larvae increased rapidly with length. This was probably due to the functional development of auditory bullae. The proportion of responding larvae that successfully escaped an attack (response effectiveness) increased throughout the larval period, as did predator errors. Increases in responsiveness, response effectiveness, and predator error rate contributed to a decline in capture probability as larvae grew. Nevertheless, in mesocosms the number of larvae consumed in 8 h by 1 predator increased with larva length, suggesting that encounter rate and possibly attack rate increased with larva length, probably due to increased conspicuousness of larvae.
\end{abstract}

\section{INTRODUCTION}

Larger fishes are capable of exerting high predation pressure on populations of fish larvae (Fuiman \& Gamble 1988). For an individual larva, surviving potential predation mortality requires predator avoidance (minimizing encounters with predators) or predator evasion (minimizing capture success of an attacking predator). Both tactics rely on sensory and motor systems and therefore are expected to be affected by growth, development, and the concurrent changes in the physiological capabilities of larvae.

Vulnerability (V), the probability of being consumed by a predator, can be viewed as the product of 3 component probabilities (modified from O'Brien 1979):

$$
\mathrm{V}=\mathrm{P}_{\mathrm{E}} \cdot \mathrm{P}_{\mathrm{A}} \cdot \mathrm{P}_{\mathrm{C}}
$$

where $P_{E}=$ probability of an encounter between predator and prey; $\mathrm{P}_{\mathrm{A}}=$ probability of attack by the predator; and $\mathrm{P}_{\mathrm{C}}=$ probability of capture. This definition disregards the trivial mortality due to fatal wounds inflicted by an unsuccessful attack. Such mortality occurred in $1.5 \%$ of attacks by 15 to $35 \mathrm{~mm}$ cape anchovy Engraulis capensis on smaller conspecifics (Brownell

\footnotetext{
- Contribution no. 729 of the University of Texas at Austin Marine Science Institute
}

1985) and would be less frequent when larger, more competent predators are involved.

Both development and growth of fish larvae affect the component probabilities of vulnerability. Although these 2 processes are difficult to measure separately, their effects on vulnerability are conceptually distinct. Development of sensory and motor systems during the larval period should decrease vulnerability (Hunter 1981, Blaxter 1986) as a larva becomes better equipped to detect a predator and avoid it (reducing $\mathrm{P}_{\mathrm{A}}$ ) or escape (reducing $\mathrm{P}_{\mathrm{C}}$ ). Increasing size and the allometric apportionment of growth (Fuiman 1983) provides greater power from larger propulsive muscles. Larger size also confers hydrodynamic advantages (Weihs 1980, Webb \& Weihs 1986) and limits the number of predators capable of ingesting a larva. Conversely, an older larva is generally more conspicuous by virtue of its size, opacity, and pigmentation. Increased conspicuousness is directly related to encounter probability (Kerfoot 1980, Endler 1986). Larger larvae also have greater food value to predators, however their enhanced evasive ability reduces net profitability.

In summary, vulnerability of larvae to predatory fishes is subject to antagonistic influences attributable to development and growth. An accurate predictive model for age-related changes in vulnerability requires knowledge of the nature and timing of these 
influences. The present study examines Atlantic herring Clupea harengus larvae as prey of yearling herring. The goal was to quantify relative changes in vulnerability and its components during ontogeny. Attention was focussed on the larvae as prey and experimental conditions were designed to have minimal effect on their behavior.

\section{MATERIALS AND METHODS}

Laboratory. Laboratory procedures conducted at the Dunstaffnage Marine Research Laboratory were designed to measure the capture probabilities of herring larvae by a biting fish. Yearling herring was chosen as a convenient model predator. They coincide with, and probably prey upon, herring larvae in the sea. The predators used in laboratory experiments ranged from 6.6 to $8.4 \mathrm{~cm}$ in length in 1986 and 8.1 to $10.4 \mathrm{~cm}$ in 1987

To obtain larvae, gonads were taken from ripe adults collected in 1986 and 1987 on Ballantrae Bank in the Firth of Clyde, off the west coast of Scotland. Eggs were artifically fertilized in the laboratory and dispersed among 3 rearing tanks supplied with filtered flowthrough circulation. Water temperature in the rearing tanks varied with that of the sea, from about 7 to $14{ }^{\circ} \mathrm{C}$ between April and July. Fluorescent lights provided an intensity of 100 lux at the water surface from natural dawn to dusk daily. When larvae had absorbed nearly all yolk they were fed daily on Artemia sp. nauplii supplemented with natural zooplankton once daily. Larvae to be used as prey were taken from these rearing tanks.

Experiments were conducted in an air-conditioned room maintained at $8{ }^{\circ} \mathrm{C}$. Trials were conducted at 2 temperatures: 8 and $15^{\circ} \mathrm{C}$ in 1986,8 and $11^{\circ} \mathrm{C}$ in 1987. Stock and trial tanks were maintained at these temperatures with immersed heaters. Fluorescent lights provided an intensity of 150 lux at the water surface from 06:00 to 20:00 h daily. Two predators resided in each of two $76 \mathrm{~cm}$ diameter circular black trial tanks, each tank filled to a depth of $18 \mathrm{~cm}$. Predators from the stock tanks were used to replace the few individuals that became ill or died. Predators in the trial tanks were given pelleted food every other day between trials but not during the $2 \mathrm{~d}$ preceding a trial. Although some of the predators became 'trained' to the experimental conditions, there were no measurable changes in attack behavior that could be thought to affect the evasive behavior of older, yet naive larvae.

Predation trials were always conducted between 15:30 and 17:00 h. Trials were on closely spaced days during the first $60 \mathrm{~d}$ of the larval period coinciding with a time of rapid morphological development. The inter- val between trials was expanded for older larvae. For each predation trial a $45 \mathrm{~cm}$ plastic disc covered with retroreflective material (Scotchlite) was placed on the bottom of each trial tank. An opaque plastic pipe $(10 \mathrm{~cm}$ diameter $\times 20 \mathrm{~cm}$ high) was centered on each disk and usually 50 larvae placed within each pipe. When larvae grew to about $20 \mathrm{~mm}$ in length, 20 or fewer individuals were used. These were left undisturbed (except for a feeding of Artemia on the day preceding experimentation) for $2 \mathrm{~d}$ to allow thermal acclimation. Trials began by lifting the pipe vertically, exposing the larvae to the predators.

A video camera mounted above the tank recorded subsequent predation events reflected in a semisilvered mirror. A $15 \mathrm{~W}$ xenon strobe shone through the mirror. Its light was reflected directly back from the disk providing silhouette images of the predators and prey at $20 \mathrm{~ms}$ intervals. Light intensity at the water surface during predation bouts was 95 lux.

Observations made during field-by-field playback of the video tapes included the occurrence of: an attack by the predator, a response by the prey, and a capture by the predator. An attack occurred when a predator accelerated toward, and attempted to consume, a larva which lay directly ahead. Only responses of larvae following the onset of an attack and characterized by rapid acceleration, including an initial ' $\mathrm{C}$ ' or ' $\mathrm{S}$ ' posture were counted. These were deemed escape attempts. Obvious avoidance behavior - maneuvering by the prey to prevent an attack - was not obserbed. When an attack was unsuccessful (no capture) it was scored as an escape if the prey had responded and a predator error if a response could not be seen.

Raw data, recorded as 0 for absence of an event and 1 for presence, were binomially distributed. Mean values were calculated for all observational variables after grouping data by $1 \mathrm{~mm}$ intervals of larva length. Such large sample means from a binomial distribution tend to be normally distributed, thereby permitting the use of more rigorous statistical procedures. Results from all temperatures were combined because differences in the variables discussed here were not significant or were small with respect to changes with age (Fuiman unpubl.).

Observational variables were related to larva length to identify age-related changes because both growth and development are more closely associated with length than with age (Gerking \& Rausch 1979, Fuiman \& Webb 1988). Growth curves (Fig. 1, Table 1) were established for larvae in the rearing tanks in each year by measuring individual total lengths in samples that were fixed in $4 \%$ buffered formalin. Curves were fitted to growth data and observational data by least squares, nonlinear regression. For observational data, values in the regressions (means for larvae within $1 \mathrm{~mm}$ intervals 
Table 1. Equations and statistics for curves presented in Figs. 1 to $7 X$ represents length of larvae in mm, except as noted. $R^{2}$ : proportion of the total variance in $Y$ accounted for by regression. SY.X: standard error of the residuals. All regressions are significant at the 0.05()$\left.^{\circ}\right)$ or $0.01(\cdots)$ level of significance

\begin{tabular}{|c|c|c|c|c|c|}
\hline Fig. & Independent variable & Equation & $n$ & $R^{2}$ & $S_{Y x}$ \\
\hline \multirow[t]{3}{*}{1} & Length ( $X=$ age in days) & & & & \\
\hline & 1986 & $Y=8.455(0.947 \exp (1-\exp (-0.020 X)\})$ & 154 & $0.87^{\cdots}$ & 1.13 \\
\hline & 1987 & $Y=9.580+0.009 X^{1.615}$ & 189 & $0.90 \cdots$ & 1.93 \\
\hline 2 & Larvae responding & $Y=6.195+60.380(\exp (-\exp (-10.602(X / 10-2.840))))$ & 1067 & $0.95 \cdots$ & 3.79 \\
\hline 3 & Larvae escaping & $Y=120.913-79.553 /(X / 10)$ & 144 & $0.44^{\cdots}$ & 21.08 \\
\hline 4 & Predator errors & $Y=10.532+250.325(\exp (-\exp (-0.861(X / 10-3.369))))$ & 938 & $0.89 \cdots$ & 8.51 \\
\hline 5 & Larvae caught & $Y=2.823+83.509(\exp (-\exp (3.273(X / 10-2.791))))$ & 1065 & $0.90^{\circ}$ & 8.62 \\
\hline 6 & Vulnerability & $Y=42.343-31.108 /(X / 10)-3.890(X / 10)$ & 22 & $0.19^{\circ}$ & 7.89 \\
\hline $7 a$ & Vulnerability/capture prob. & $Y=40.039-31.783 /(X / 10)$ & 22 & $0.24 \cdots$ & 9.02 \\
\hline $7 \mathrm{~b}$ & Lateral body area & $Y=0.0075 X^{2.759}$ & 162 & $0.98 \cdots$ & 1.80 \\
\hline $7 \mathrm{~b}$ & Swimming speed & $Y=0.262 X^{1.875}$ & 32 & $0.90^{\cdots}$ & 6.82 \\
\hline $7 \mathrm{~b}$ & Activity & $Y=96.604 \exp (-\exp (-6.605(X / 10-0.928)))$ & 31 & $0.95 \cdots$ & 4.45 \\
\hline
\end{tabular}

of length) were weighted by the number of observations comprising each to minimize the influence of less reliable points. Regression statistics $\left(\mathrm{S}_{y \cdot x}, R^{2}\right)$ and significance tests $(F)$ were calculated from unweighted means. Although results are discussed in terms of larva length, the reader should not construe this as meaning that observed changes are a function of larva size per se. Effects of developmental progress will also be present.

Enclosures. Age-related changes in gross vulnerability were estimated by conducting experiments in 8 large enclosures (mesocosms). These experiments were performed at the field laboratory of the Department of Agriculture and Fisheries for Scotland, on Loch Ewe, near Poolewe in northwestern Scotland. The enclosures were suspended from a raft moored in Thurnaig Bay and were described in detail by Fuiman \& Gamble (1988). Briefly, they enclosed $15.8 \mathrm{~m}^{3}$ of water, were $6.5 \mathrm{~m}$ deep, $2 \mathrm{~m}$ in diameter, and made of opaque black PVC sheeting $(0.54 \mathrm{~mm}$ thick). The lower $1.5 \mathrm{~m}$ formed a cone terminating in a plugged $20 \mathrm{~cm}$ drain fitted with a $250 \mathrm{um}$ mesh bag. Light intensity in the enclosures ranged from 170 lux at the bottom to 7500 lux at the surface.

Four experiments (32 trials) were conducted in 1987 (14 to 17 April, 1 to 4 May, 30 May to 2 June, 9 to 10 September) where in each enclosure 400 larvae were exposed to a single predator for $8 \mathrm{~h}$. Ancillary experiments using very young larvae for various durations and stocking densities showed that this combination provided sufficient predation to allow measurement of either a decrease or increase in predation rate as larvae grew. The first 3 periods represent experiments using larvae obtained and reared similarly to those used in the laboratory trials and averaging $11.4,13.5$, and 16.8 $\mathrm{mm}$ in total length (measured alive). Attempts to obtain a sufficient number of larger herring larvae $(22 \mathrm{~mm})$ for enclosure experiments failed because they were too delicate to tolerate transport. The September experi- ment used larvae reared from gametes taken from ripe adults collected on Aberdeen Bank, northeastern Scotland on 21 August 1987 . These were treated similarly to the other larvae; details were given by Fuiman \& Gamble (1988). These larvae averaged $8.9 \mathrm{~mm}$ during the experiment.

Predators were collected as 0-group herring in Dunstaffnage Bay, near Oban, in August 1986, transported to the field site $2 \mathrm{wk}$ later, and kept for several months before use. They were fed pelleted salmon food throughout captivity except during the $2 \mathrm{~d}$ preceeding an experiment. Significant mortality ceased after 4 to 6 $w k$, presumably leaving those individuals that could cope with captivity and experimental conditions. During experiments, they averaged 15.3, 15.2, 16.0, and $18.1 \mathrm{~cm}$ in length, respectively.

During each experiment, water was pumped into each enclosure through a $40 \mu \mathrm{m}$ mesh plankton net to exclude alternative prey for the predators. Four hundred larvae were added to each enclosure and allowed to acclimate and disperse overnight. One predator was added to each enclosure at 07:00 h on the next day. Use of a single predator was necessary to obtain repeatable results. Gamble \& Fuiman (1987) found that when more than 1 herring was used, results were highly variable and difficult to interpret. Because herring normally feed in schools, their foraging behaviour and predation rate in these experiments were probably not normal. Nevertheless, relative changes in predation rate with larva length are indicative of the natural trend.

After $8 \mathrm{~h}$ a 1:4 mixture of Quinaldine (2-methylquinoline) and acetone was added to each enclosure by filling a nylon tube lowered to the bottom of the enclosure then lifting the tube out. The final Quinaldine concentration of $10 \mathrm{ppm}$ was sufficient to anaesthetize the predators to terminate predation while each enclosure was lifted and its contents drained through the 
mesh bag at the bottom which was subsequently immersed in $5 \%$ formalin to fix the larvae.

Mortality of larvae during transportation from the field laboratory to the enclosures was less than $1.7 \%$. Control trials, in which no predators were added, showed the counting and recovery methods to be $98.4 \%$ accurate (Fuiman \& Gamble 1988). The $95 \%$ confidence interval for control enclosures entended down to 387 larvae remaining. Therefore trials in which more than 386 larvae remained after an $8 \mathrm{~h}$ exposure to the predator were disregarded, since the possibility of abnormal predator behavior, due to effects of handling, could not be rejected. This resulted in an unbalanced number of enclosures among the experiments.

\section{RESULTS}

\section{Laboratory}

Growth rates for larvae in the rearing tanks were similar in 1986 and 1987 (Fig. 1). The trends diverged after about 70 d, with 1986 fish being smaller than 1987 fish.

Trials conducted in 1986 began when larvae were $4 \mathrm{~d}$ posthatching and continued until they were $101 \mathrm{~d}$ old when there were insufficient larvae (due to experimentation) to continue. In 1987, trials began later $118 \mathrm{~d}$ posthatching) but continued through $118 \mathrm{~d}$, resulting in offset ranges of lengths in the 2 yr (Table 2). If there had been no age-related effects on predation bouts the data in Table 2 would indicate that the observational variables were highly variable. However, age-related changes accounted for much of the variation.

\section{Prey responsiveness}

The proportion of larvae responding to an attack was surprisingly low for larvae less than $26 \mathrm{~mm}$, usually less than $10 \%$ (Fig. 2). There was a small but statistically significant decline in response rate with larva length up to $26 \mathrm{~mm}$. However, the linear regression accounted for only $38 \%$ of the variation in responsiveness up to that size ( $r=0.614, n=854)$. It is more reasonable to assume that the response rate remained constant during this period (at the mean of $6.2 \%$ ) and that the significant regression was an artifact of the decreasing rate of experimentation as larvae grew. The response rate of older larvae $(>26 \mathrm{~mm})$ increased rapidly with length.

This change in response rate was almost certainly caused by the functional development of the auditory bullae, accessory hearing organs found in herring and other clupeoids (Blaxter et al. 1981). The timing of the

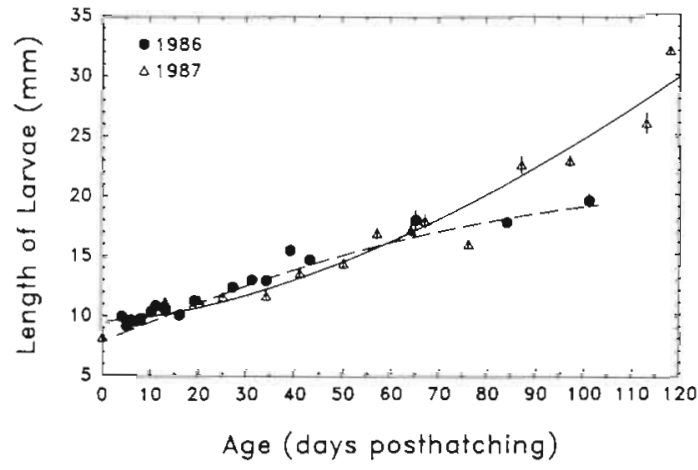

Fig. 1. Clupea harengus. Laboratory growth of herring larvae. Mean total lengths ( $\pm 1 \mathrm{SE}$ ) are plotted for preserved larvae. Table 1 contains equations for curves

Table 2. Summary of observations for laboratory predation experiments

\begin{tabular}{lccc|}
\hline Observational variable & \multicolumn{3}{c}{ Year } \\
& 1986 & 1987 & Total \\
\hline Larva length (mm, TL) & $8.6-19.1$ & $10.5-32.0$ & $8.6-32.0$ \\
Trials & 34 & 42 & 76 \\
Attacks & 408 & 659 & $1067^{\text {a }}$ \\
Responses & 39 & 105 & 144 \\
Escapes & 20 & 88 & 108 \\
Predator errors & 43 & 166 & 209 \\
Captures & 344 & 404 & 748 \\
a The outcome of 2 attacks was uncertain and not scored \\
\hline
\end{tabular}

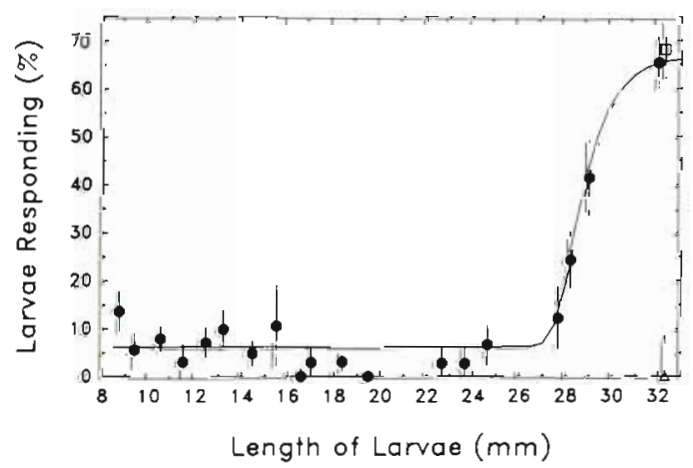

Fig. 2. Clupea harengus. Responsiveness. The proportion of larvae responding to attack. ( $\bullet$ Means ( $\pm 1 \mathrm{SE}$ ) for all larvae within $1 \mathrm{~mm}$ intervals of lengthi $\Leftrightarrow$ larvae with gas in the auditory bullae; (1) larvae without gas in the bullae. Average number of observations per $(\bullet)$ mean $=56$ (range: 15 to 127$)$.

Table 1 contains equation for curve fitted to the circles

appearance of gas in the bullae coincided with the rapid increase in responsiveness. The following observations were made in 1987 . Of ten 97-d-old larvae (mean length: $24.1 \mathrm{~mm}$ ) sampled from the rearing tank but not used in predation trials 3 possessed gas in their bullae. The mean response rate at this size was low 
(6.2\%, Fig. 2). At 113 d, 6 of 10 larvae sampled contained gas in their bullae. On that day the mean length of larvae in the rearing tanks was $28.2 \mathrm{~mm}$ and the response rate for that trial was $24.2 \%$. Five days later (Day 118$) 21$ of 23 larvae $(91 \%$ ) averaging $32.0 \mathrm{~mm}$ had gas in the bullae and the response rate for 13 of these 23 individuals was $65.3 \%$. This last value combines the results of 2 trials, one with 11 larvae having gas in their bullae and one with 2 larvae lacking gas. The larvae lacking gas showed no responses in 3 attacks (1 predator error, 2 captures). The larvae with gas-filled bullae were highly responsive to attacks: responses in $68.1 \%$ of 69 attacks (Fig. 2).

\section{Response effectiveness}

The low response rate substantially reduced the data set to be used for determining the change in the ability of responding larvae to escape successfully. Generally, response effectiveness increased throughout development (Fig. 3). By $32 \mathrm{~mm}$, no responding larvae were caught by attacking predators.

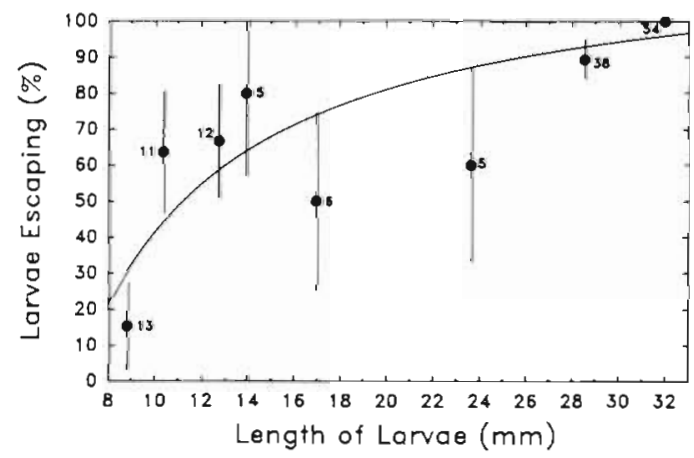

Fig. 3. Clupea harengus. Response effectiveness. Proportion of responding larvae (Fig. 2) that escaped successfully. Data points are means ( $\pm 1 \mathrm{SE}$ ) for adjacent size classes of larvae. Sample size for each point is shown. Table 1 contains equation for curve

\section{Predator errors}

Predators always struck at larvae they attacked; no attacks were aborted. Predators failed to catch nonresponding larvae more frequently as larvae became larger (Fig. 4). The nature of these errors changed with larva length. Errors involving smaller larvae almost always left them in the location they occupied before the attack or moving in the turbulence created by the predator but without body movements of their own. Larger larvae were often seen in the predator's 'grasp' but with most of their body outside the predator's mouth. The predator's failure to swallow the larva after

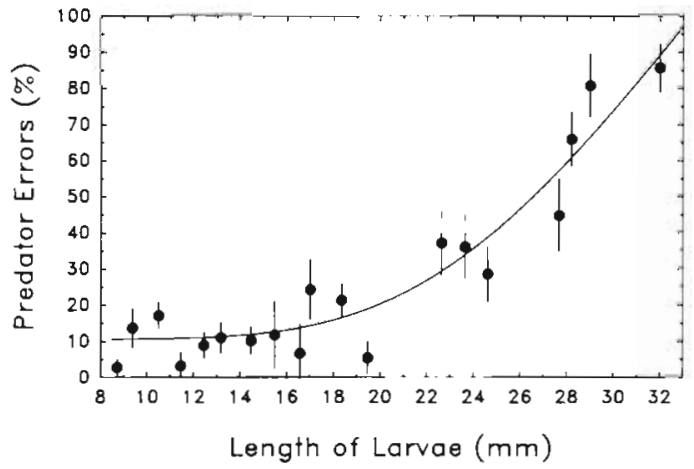

Fig. 4. Clupea harengus. Proportion of attacks on nonresponding larvae in which the predator failed to catch the prey. Data points are means ( $\pm 1 \mathrm{SE}$ ) for all larvae within 1 $\mathrm{mm}$ intervals of length. Table 1 contains equation for curve

seizing it may have been the result of poor handling (an error) or wriggling free by the prey (a late, but successful escape). It was not possible to distinguish these alternatives after the predator had closed its jaws on the prey. Therefore, unless an escape response was observed, the event was recorded as a predator error.

\section{Probability of capture}

The increases in responsiveness, response effectiveness, and predator error rate all contributed to a general decline in the probability that an attacked larva was consumed $\left(\mathrm{P}_{\mathrm{C}}\right)$, as larvae developed and grew. Capture probability averaged about 0.90 for smallest larvae, dropping slowly to 0.50 at $26 \mathrm{~mm}$, and 0.10 near $30 \mathrm{~mm}$ (Fig. 5). Although both escapes and predator errors contributed, errors dominated the outcome of predation bouts before gas appeared in the auditory bullae.

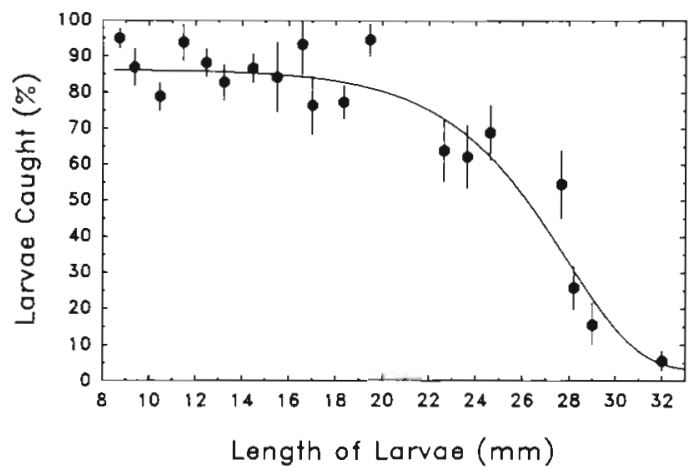

Fig. 5. Clupea harengus. Proportion of attacks in which a larva was caught. Data points are means ( $\pm 1 \mathrm{SE}$ ) for all larvae within $1 \mathrm{~mm}$ intervals of length. Table 1 contains equation for curve 


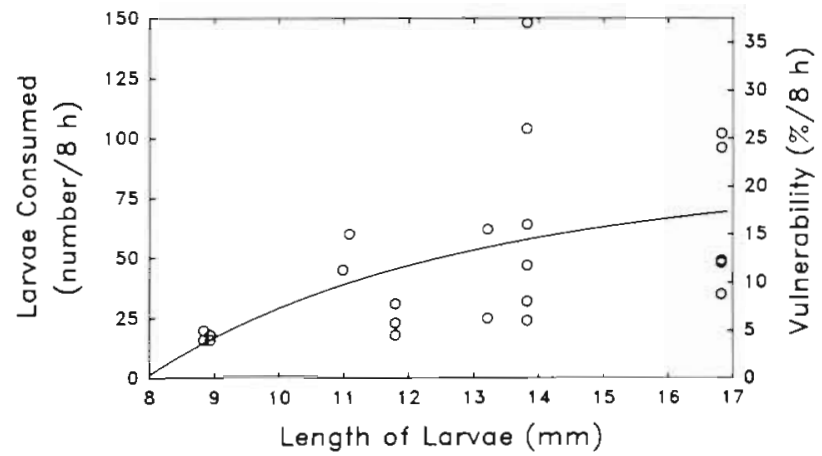

Fig. 6. Clupea harengus. Number of larvae consumed (out of 400 ) and their vulnerability during an 8 h exposure to predators in mesocosms. Data points represent results from individual trials. Table 1 contains equation for curve

\section{Enclosures}

Gross vulnerability, as measured in the mesocosm experiments, contradicted the laboratory findings. In mesocosms, the number of larvae consumed by the predators in $8 \mathrm{~h}$ increased with length of the larvae (Fig. 6). The rate of increase declined with larva length. Since the mesocosm results incorporate all components of vulnerability and the laboratory results measure only $P_{C}$, the discrepancy indicates important age-related changes in $\mathrm{P}_{\mathrm{E}}$ or $\mathrm{P}_{\mathrm{A}}$.

\section{DISCUSSION}

\section{Age-related changes in vulnerability}

Laboratory experiments demonstrated that evasive behavior of the larva and competence of the predaor affect capture probability. The increase in escape success of responding larvae over a wide range of lengths (Fig. 3) suggests that the enhancement of motor skills is important to predator evasion. But sensory development appears to constrain evasive behavior. The development of additional sensory capabilities after about $26 \mathrm{~mm}$ complements the well-developed motor skills to reduce capture probability markedly at larger sizes (Fig. 5). The apparent decline in predator competence probably results from the combined effects of the unwieldy nature of relatively large prey and late escape attempts.

In the context of the probability model for vulnerability, the equation for larvae caught (Table 1) provides estimates of capture probability, $\mathrm{P}_{\mathrm{C}}$ for attacked herring larvae from hatching through $32 \mathrm{~mm}$ (most of the larval period). Enclosure experiments measured the change in gross vulnerability, $V$, over a smaller range of lengths (hatching through $17 \mathrm{~mm}$ ). Vulnerability

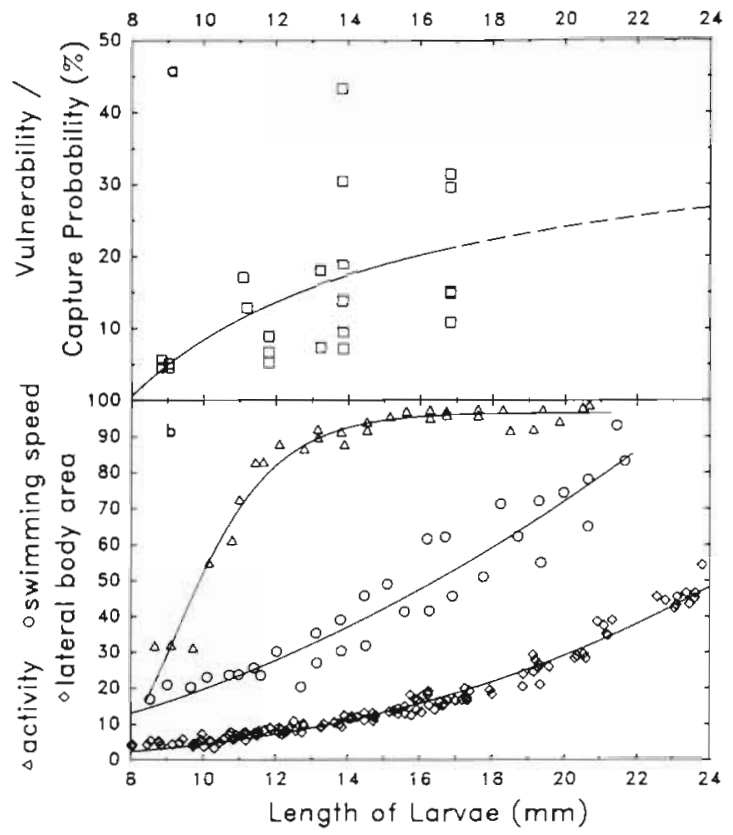

Fig. 7 Clupea harengus. Vulnerability excluding capture probability $\left(=\mathrm{P}_{\mathrm{E}} \cdot \mathrm{P}_{\mathrm{A}}\right)$ and components of encounter probability. (a) Data points represent mesocosm results (Fig. 6) divided by predicted capture probability (Table 1). (b) Lateral body area $\left(\mathrm{mm}^{2}\right)$ was measured from video images of preserved specimens by an IBAS 2000 image-analysis system. Data for swimming speed ( $\left.\mathrm{cm} \mathrm{min}^{-1}\right)$ and activity $(\%$ of time) were taken from Blaxter \& Staines (1971) and Ehrlich et al. (1976). Table 1 contains equations for curves

increased with larva length, despite a small decrease in capture probability over this period. Therefore, either or both of the remaining components of vulnerability, encounter probability $\left(P_{E}\right)$ and attack probability $\left(P_{A}\right)$, must have increased. The contribution of capture probability to vulnerability can be eliminated by dividing observed values of vulnerability by estimates of capture probability predicted by the equation in Table 1. The result is the product of the probabilities of encounter and attack, and this shows an increasing trend that slows with increasing larva length (Fig. 7 a).

What age-related changes might serve to increase encounter and attack probabilities? Encounter probability should increase with larva length through increases in both the routine swimming speed and conspicuousness (morphological and behavioral) of larvae. Herring larvae swim about 2.3 times as fast at $17 \mathrm{~mm}$ as they do at $9 \mathrm{~mm}$ (Fig. 7b). However, a mathematical model for encounter rate developed by Gerritsen \& Strickler (1977) suggests that when the speed of the prey is small relative to that of the predator, as it was in these experiments, even large increases in prey speed have only small effects on encounter rate. According to that model, the 2.3-fold increase in the speed of herring larvae translates into only a $0.4 \%$ increase in encounter 
rate at the mean predator foraging speed of $8.2 \mathrm{~cm} \mathrm{~s}^{-1}$ measured during the final mesocosm experiment. Thus, age-related changes in swimming speed of larvae probably accounted for very little of the $87 \%$ increase between 9 and $17 \mathrm{~mm}$ in Fig. $7 \mathrm{a}$

Morphological conspicuousness is a very potent factor contributing to encounter probability (O'Brien 1979) and its importance to larval fish vulnerability was inferred by Folkvord \& Hunter (1986). It is measured as encounter radius in Gerritsen \& Strickler's model, which predicts large changes in encounter rate from small changes in encounter radius. Changes in environmental conditions (light intensity, turbidity, background color and texture) may render larvae more visible or less visible to predators (Vinyard \& O'Brien 1976) but such factors do not explain the trend in Fig. $7 \mathrm{a}$.

Herring larvae become more visible with age because they become larger, less transparent, and more pigmented. The change in lateral body area, exclusive of finfolds and fins, exemplifies the increase in visible size of herring larvae with age (Fig. $7 \mathrm{~b}$ ). Lateral body area is only a guide to the nature of the change in visibility with age. In one sense, it overestimates the predator's visual experience since a predator will not always encounter a larva oriented perpendicular to its line of sight. On the other hand, lateral area does not include measures of opacity and pigmentation, which increase with age. Brownell (1985) found that cape anchovy larvae with pigmented eyes were detected more often by predatory fishes than only slightly smaller larvae that lacked retinal pigment.

Behavioral changes also alter the conspicuousness of a larva. Most predators are more likely to react to moving prey (Ware 1973, Zaret 1980, Janssen 1982). The proportion of time spent actively swimming increases with age during the larval period of most species of marine fishes (Hunter 1981). For herring larvae, the increase in activity with age coincides with the increase in their vulnerability (Fig. 7).

The characteristics that effect encounter probability (increasing conspicuousness and swimming speed) probably account for much of the observed increase in vulnerability of growing herring larvae. Changes in $P_{A}$ may also be important but they are difficult to quantify. The ability of a larva to detect a nearby predator and maneuver away to avoid an attack may increase with length. In addition, a predator's 'interest' in consuming a larva may change with larva length, as predicted by optimal foraging theory (tradeoff between increasing value of larger larvae and greater energetic expense to capture them).

\footnotetext{
- Predator foraging speed was measured from video recordings of individual predators in a black, $1.5 \mathrm{~m}$ circular tank located outdoors (see Fuiman \& Gamble 1988 for details)
}

However, it is unlikely that during the course of an enclosure experiment predator motivation (hunger) decreased more when larger larvae were consumed. Hourston et al. (1981) found that juvenile herring fed ad libidum consumed herring larvae at a rate of more than $1 \mathrm{~min}^{-1}$ even after $10 \mathrm{~h}$ of feeding. Given this voracity (supported by the present laboratory experiments and those of O'Brien 1979), satiation would not seem to be a concern.

If the factors affecting $P_{E}$ and $P_{A}$ for larvae between 9 and $17 \mathrm{~mm}$ continued along the same trends through $32 \mathrm{~mm}$ (as is the case for the factors shown in Fig. $7 \mathrm{~b}$ ), vulnerability could be predicted as the product of the curves in Fig. 7a and Fig. 5: a broadly dome-shaped curve with maximal vulnerability at lengths near 18 to $20 \mathrm{~mm}$. Indeed, vulnerability in the mesocosms would have to have declined at larger sizes because $P_{C}$ approached zero at $32 \mathrm{~mm}$. At that point, predators could not catch the prey regardless of the encounter and attack rates.

\section{Stimulus for an evasive response}

In herring, responsiveness to attacking fishes increases sharply at the time when the auditory bullae fill with gas and lateral line canals form. Most other sensory systems are functional long before herring attain $26 \mathrm{~mm}$. The observation that the few large larvae that lacked gas in the bullae at $118 \mathrm{~d}$ posthatching failed to respond to attacks (Fig. 2) supports (albeit weakly) the importance of the bullae. However, since $6 \%$ of larvae respond before bullae are functional, other sensory systems are capable of perceiving a predator and triggering an evasive response.

The startle response used by larvae in their evasive behavior probably involves the Mauthner neuron (Eaton \& Hackett 1984). This neuron has connections to the inner ear in fishes and other connections are suspected (Eaton et al. 1984). Blaxter \& Batty (1985) showed that herring larvae exhibit startle responses to mechanical acoustic stimuli only if the bullae contain gas. Recent experimentation suggests that free neuromasts may also trigger a startle response in fish larvae (Blaxter \& Fuiman 1989). In herring, it appears as though the stimulus that elicits an evasive maneuver from an attacking fish is primarily acoustic, received through the bullae, lateral line, and perhaps the free neuromasts.

Auditory bullae may not play such an important role in predator detection for other clupeoid larvae, at least at small sizes. In northern anchovy Engraulis mordax the bullae fill with gas by $12 \mathrm{~mm}$ (O'Connell 1981). Yet, 2 species of anchovies (E. mordax and E. capensis) show a substantial increase in responsiveness with length at less than $12 \mathrm{~mm}$ (Brownell 1985, Folkvord \& 
Hunter 1986). Northern anchovy and Pacific sardine Sardinops sagax larvae show increased responsiveness from the earliest posthatching stages with no obvious acceleration that might be due to bullae becoming functional (Butler \& Pickett 1988). Webb (1981) believed the evasive response of northern anchovy larvae is mediated by the eye. Folkvord \& Hunter (1986) concurred and implicated the neuromasts. Both of these systems are at least partly functional before 26 $\mathrm{mm}$ in herring and by $4 \mathrm{~mm}$ in anchovies $\left(\mathrm{O}^{\circ}\right.$ Connell 1981).

\section{Evolutionary considerations}

The observation that herring larvae as small as 12 $\mathrm{mm}$ that respond to an attack have a greater than $50 \%$ chance of surviving the encounter, whereas nonresponding, $12 \mathrm{~mm}$ larvae have an $11 \%$ chance, suggests strong evolutionary pressure to develop an ability to respond to predators at smaller sizes. This could be accomplished by earlier filling of the auditory bullae or early development of some other sensory capability. Anchovies and Pacific sardine appear to have done both, thereby reducing their risk of being caught when a fish attacks. Still, it is possible that there is little selection pressure for herring to develop responsiveness early. That is, they may not experience much risk from predatory fishes in their natural offshore nursey grounds.

Two differences that may be worth note are: (1) herring were studied at colder temperatures $\left(8\right.$ to $\left.15^{\circ} \mathrm{C}\right)$ than the anchovies and sardine $\left(17\right.$ to $\left.19^{\circ} \mathrm{C}\right)$; and (2) eggs of Clupea harengus are demersal but all other known marine clupeoid eggs are pelagic (Blaxter \& Hunter 1982). Temperature effects on responsiveness are not substantial. I did not find an increase in responsiveness at smaller sizes when herring larvae were tested in warmer water (unpubl.). In terms of spawning locale, Blaxter \& Hunter (1982) pointed out that the deposition of demersal, adhesive eggs allows larvae to be produced at a specific place and time so that they might coincide with predictable periods of favorable conditions for survival. Pelagic eggs in cold waters, having long incubation periods, may be scattered more unpredictably during incubation. Perhaps the delayed responsiveness of herring is linked to this difference or some other characteristic of larvae from pelagic eggs

\section{Future research directions}

To date, laboratory studies of age-related changes in evasive behavior of fish larvae have been confined to 4 clupeoids: Engraulis mordax (Webb 1981, Folkvord \&
Hunter 1986), E. capensis (Brownell 1985), Sardinops sagax (Butler \& Pickett 1988), and Clupea harengus (this paper). One study (Margulies unpubl.) examined a sea bass Atractoscion nobilis. Among the clupeoids (2 engraulids and 2 clupeids), only $C$. harengus shows an obvious reliance on the auditory bullae for responding to a predator. Additonal studies of clupeoids, especially species closely related to Atlantic herring (such as Brevoortia tyrannus, ) are needed. More studies of nonclupeoids are necessary to determine if general trends in age-related changes in vulnerability exist for large groups of fishes.

Although laboratory work is important for identifying the mechanisms of changing vulnerability, mesocosm experiments provide the more complete data on vulnerability. Without complimentary mesocosm studies, the logical but incorrect conclusion from the laboratory studies listed above is that vulnerability decreases throughout development. This trend is masked by more powerful influences not addressed in laboratory studies.

The work reported here describes changes in vulnerability to one species and size of predatory fish. As larvae become invulnerable to a particular size of predator, they remain vulnerable to larger fishes. In order to model age-related changes in the vulnerability of wild populations, the effects of predator species and size must be considered

Acknowledgements. I am indebted to Professor John H. S Blaxter and Dr John C. Gamble for their important contributions to this project. They, together with Dr Robert S. Batty, gave valuable assistance in all phases of experimentation. I appreciate the help of Philip MacLachlan, Dr Gidon Minkoff, Duncan Seaton, and Ming-Cheng Yin during the study. I thank Professor R. 1. Currie and Dr A. D. Hawkins, directors of the Scottish Marine Biological Association and the Marine Laboratory. Department of Agriculture and Fisheries for Scotland, respectively, for their facilities and support. Professors Blaxter and Paul W Webb, Dr Gamble, and 2 anonymous referees provided constructive reviews of the manuscript. This material is based upon work supported by the National Science Foundation (U.S.) under Grant BSR-8503058 awarded in 1985.

\section{LITERATURE CITED}

Blaxter, J. H. S. (1986). Development of sense organs and behaviour of teleost larvae with special reference to feeding and predator avoidance. Trans. Am. Fish. Soc 115: $98-114$

Blaxter, J. H. S. Batty, R. S. (1985). The development of startle responses in herring larvae. J. mar. biol. Ass. U. K. 65: $737-750$

Blaxter, J. H. S., Denton, E. J., Gray, J. A. B. (1981). The auditory bullae - swimbladder system in late stage herring larvae. J. mar biol. Ass. U. K. 61. 315-326

Blaxter, J. H. S. Fuiman, L. A. (1989). Function of the free neuromasts of marine teleost larvae. In: Coombs, S. 
Görner, P., Münz, H. (eds.) The mechanosensory lateral line: neurobiology and evolution. Springer-Verlag, New York, p. 481-499

Blaxter, J. H. S., Hunter, J. R. (1982). The biology of the clupeoid fishes. Adv. mar Biol. 20: 1-223

Blaxter, J. H. S., Staines, M. E. (1971). Food searching potential in marine fish larvae. In: Crisp, D. J. (ed.) Proceedings of the fourth European marine biology symposium. Cambridge University Press, London, p. 467-485

Brownell, C. L. (1985). Laboratory analysis of cannibalism by larvae of the cape anchovy Engraulis capensis. Trans. Am. Fish. Soc. 114: 512-518

Butler, J. L., Pickett, D. (1988). Age-specific vulnerability of Pacific sardine, Sardinops sagax, larvae to predation by northern anchovy, Engraulis mordax. Fish. Bull. U.S. 86: 163-167

Eaton, R. C., Hackett, J. T (1984). The role of the Mauthner cell in fast starts involving escape in teleost fish. In: Eaton, R. C. (ed.) Neural mechanisms of startle behavior. Plenum Press, New York, p. 213-266

Eaton, R. C., Nissanov, J., Weiland, C. M. (1984). Differential activation of Mauthner and non-Mauthner startle circuits in the zebrafish: implications for functional substitution. J. Comp. Physiol. A 155: 813-820

Ehrlich, K. F., Blaxter, J. H. S., Pemberton, R. (1976). Morphological and histological changes during the growth and starvation of herring and plaice larvae. Mar. Biol. 35: 105-118

Endler, J. A. (1986). Defense against predators. In: Feder, M. E., Lauder, G. V (eds.) Predator-prey relationships, perspectives and approaches from the study of lower vertebrates. University of Chicago Press, Chicago, p. 109-134

Folkvord, A., Hunter, J. R. (1986). Size-specific vulnerability of northern anchovy, Engraulis mordax, larvae to predation by fishes. Fish. Bull. U. S. 84: 859-869

Fuiman, L. A. (1983). Growth gradients in fish larvae. J. Fish Biol. 23: $117-123$

Fuiman, L. A., Gamble, J. C. (1988). Predation by Atlantic herring, sprat, and sandeels on herring larvae in large enclosures. Mar. Ecol. Prog. Ser. 44: 1-6

Fuiman, L. A., Webb, P. W. (1988). Ontogeny of routine swimming acitivity and performance in zebra danios (Teleostei: Cyprinidae). Anim. Behav. 36: 250-261

Gamble, J. C., Fuiman, L. A. (1987). Evaluation of in situ enclosures during a study of the importance of starvation to the vulnerability of herring larvae to a piscine predator. J. exp. mar. Biol. Ecol. 113: 91-103
Gerking, S. D., Rausch, R. R. (1979). Relative importance of size and chronological age in the life programme of fishes Arch. Hydrobiol. 13: 181-194

Gerritsen, J., Strickler, J. R. (1977). Encounter probabilities and community structure in zooplankton: a mathematical model. J. Fish. Res. Bd Can. 34: 73-82

Hourston, A. S., Rosenthal, H., Kerr, S. (1981). Capacity of juvenile Pacific herring (Clupea harengus pallasi) to feed on larvae of their own species. Can. Tech. Rep. Fish. Aquat. Sci. 1044: 1-9

Hunter, J. R. (1981). Feeding ecology and predation of marine fish larvae. In: Lasker, R. (ed.) Marine fish larvae: morphology, ecology, and relation to fisheries. Washington Sea Grant Prog., University of Washington Press, Seattle, p. 33--77

Janssen, J. (1982). Comparison of searching behavior for zooplankton in an obligate planktivore, blueback herring (Alosa aestivalis) and a facultative planktivore, bluegill (Lepomis macrochirus). Can. J. Fish. Aquat. Sci. 39: 1649-1654

Kerfoot, W. C. (1980). Commentary: transparency, body size, and prey conspicuousness. In: Kerfoot, W. C. (ed.) Evolution and ecology of zooplankton communities. Am. Soc. Limnol. Oceanogr., Spec. Symp. 3: 609-617

O'Brien, W. J. (1979). The predator-prey interaction of planktivorous fish and zooplankton. Am. Scient. 67: 572-581

O'Connell, C. P. (1981). Development of organ systems in the northern anchovy, Engraulis mordax, and other teleosts. Am. Zool. 21. 429-446

Vinyard, G. L.. O'Brien, W. J. (1976). Effects of light and turbidity on the reactive distance of bluegill (Lepomis macrochirus). J. Fish. Res. Bd Can. 33: 2845-2849

Ware, D. M. (1973). Risk of epibenthic prey to predation by rainbow trout (Salmo gairdneri). J. Fish. Res. Bd Can. 30: 787-797

Webb, P. W. (1981). Responses of northern anchovy. Engraulis mordax, larvae to predation by a model planktivore, Amphiprion percula. Fish. Bull. U.S. 79: 727-735

Webb, P. W., Weihs, D. (1986). Functional locomotor morphology of early life history stages of fishes. Trans. Am. Fish. Soc. 115: 115-127

Weihs, D. (1980). Energetic significance of changes in swimming modes during growth of larval anchovy, Engraulis mordax. Fish. Bull. U.S. 77: 597-604

Zaret, T M. (1980). The effect of prey motion on planktivore choice. In: Kerfoot, W C. (ed.) Evolution and ecology of zooplankton communities. Am. Soc. Limnol. Oceanogr., Spec. Symp. 3: 594-603 